\title{
Microstructural Mechanical Analysis of Warm-Mixed Reclaimed Semiflexible Pavement Materials with Interfacial Weakening Effect
}

\author{
Hua Tan, ${ }^{1,2}$ Weian Xuan, ${ }^{1,2}$ and Huang Wenke $\mathbb{D}^{3}$ \\ ${ }^{1}$ Guangxi Transportation Science and Technology Group Co. Ltd., Nanning 530007, China \\ ${ }^{2}$ Guangxi Key Lab of Road Structure and Materials, Nanning 530007, China \\ ${ }^{3}$ School of Civil Engineering, Guangzhou University, Guangzhou 510006, China
}

Correspondence should be addressed to Huang Wenke; h.wenke@gzhu.edu.cn

Received 15 June 2021; Accepted 13 July 2021; Published 20 July 2021

Academic Editor: Meng Guo

Copyright $(2021$ Hua Tan et al. This is an open access article distributed under the Creative Commons Attribution License, which permits unrestricted use, distribution, and reproduction in any medium, provided the original work is properly cited.

Warm-mixed reclaimed asphalt pavement technology, as an environmental recycling method to reuse waste materials, has been widely investigated around the world. However, the skeleton of the reclaimed asphalt mixture is unstable due to the existence of the reclaimed materials. Semiflexible pavement has been successfully used in heavy traffic area due to its high rutting resistance. For combination with these two methods, a warm-mixed reclaimed semiflexible pavement material was proposed in this study. In order to investigate the interfacial weakening effect of the warm-mixed reclaimed semiflexible pavement material in a microstructural perspective, an image-based two-dimensional microstructural finite element model was presented. Results show that the maximum compressive stress of the new and RAP aggregates and cement mortar with interface is greater than that without interface and the compressive stress of the material increases when considering the interface. Besides, the maximum compressive strain of the material with interface is greater than that without interface and the strain values in the models with interface at all three positions are greater than those without interface.

\section{Introduction}

Asphalt concrete, which has the advantages of smooth surface, low noise, and convenient maintenance, is one of the most common types of pavement surface materials used in the world. After some years of use, the asphalt binder becomes brittle and cracks due to oxidation of the binder and the load repetition [1]. A large amount of asphalt mixture waste from the maintenance of asphalt pavement has caused great pollution to the environment. So, great efforts have been made to reuse the waste asphalt mixture by researchers [2-8]. Reclaimed asphalt pavement (RAP) technology can not only realize the reuse of waste materials but also reduce the use of new aggregates. The RAP technology is to add appropriate amount of new asphalt binder, new aggregates, and rejuvenation into the waste asphalt material and then remix them to form a new asphalt mixture. The most commonly used way to regenerate the reclaimed asphalt pavement is to mix them at a temperature of $170^{\circ} \mathrm{C}$, which leads to the old asphalt binder in the recycle materials to age again. This will greatly weaken the performances of the asphalt mixture. Besides, hot mixing of asphalt mixture consumes a lot of energy, increases carbon dioxide emissions, and produces a lot of exhaust gases that are harmful to the environment [9-11].

In recent years, a new green environmental protection type of asphalt reclaimed material, namely, foamed warmmixing reclaimed asphalt mixture, has been used because of its low energy consumption, low emission, and decreasing aging of the old asphalt binder [12-14]. The foamed warmmixing technology of asphalt is to produce foamed asphalt binder by adding a certain proportion of water in the foaming device. When the water meets hot asphalt binder, it evaporates rapidly, and its volume expands rapidly. The 
increase of the asphalt working ability enables it to fully encapsulate aggregate at a lower temperature, so as to realize the mixing and compaction of the mixture at a lower temperature. Although the foamed warm-mixing reclaimed asphalt mixture technology can reduce the viscosity of asphalt binder so as to reduce the mixing and compaction temperature, it does not have much advantage in the aspects of high temperature performance, low temperature crack resistance, and water stability compared with the hot-mix asphalt mixture.

Semiflexible pavement, with open-graded matrix asphalt mixture (void ratio is $20-25 \%$ ) filled with special cement grouting materials, combines some of the best qualities from both flexible and rigid pavements surfaces [15]. These flexible, jointless, and water-proofing properties that characterize asphalt are accompanied by a high static bearing capacity, rutting, and wear resistance, as well as resistance to oil and fuel spillage that are characteristic of conventional concrete surfaces $[16,17]$. As a part of semiflexible pavement material, the cement grouting materials are able to interlock with the matrix asphalt mixture to form strength and then enhance the performance of the pavement. Motivated by this innovative semiflexible hybrid composite pavement type, warm-mixed reclaimed semiflexible pavement material was proposed in this study in order to improve the road performances of the foamed warm-mixed reclaimed asphalt mixture.

There are three types of interfaces in the warm-mixed reclaimed semiflexible pavement material, which are new aggregate-asphalt mastic interface, RAP aggregate-asphalt mastic interface, and cement mortar-asphalt mastic interface. These interfaces have different adhesion properties which affect the mechanical performances of the mixture. The traditional macroscopic mechanical tests are difficult to investigate the internal mechanical responses due to the interfaces. Thanks to the digital image processing technology and finite element method, researchers can gain insight into the internal structural properties of the materials in a microstructural perspective [18-20]. Many efforts of reconstruction of numerical microstructural model for asphalt mixture based on CT slices or cross-cutting images have been made to conduct virtual tests to predict micromechanical response under different loading conditions [21-23]. However, in these finite element models, interface between aggregate and asphalt mastic is not considered. Instead, the interface is assumed to be completely bound together; that is, the nodes at the interface are shared by aggregate and asphalt mastic. As a result, the mechanical response of the model under loading is different from the reality. So, it is very important to establish a more accurate microstructural numerical model including interfaces in order to accurately analyze the internal mechanical response of asphalt mixture.

In this paper, the warm-mixed reclaimed semiflexible asphalt mixture was prepared and then beam-shape cross session image of the specimen was obtained. Image-based finite element method was applied to reconstruct the microstructural digital samples of the warm-mixed reclaimed semiflexible asphalt mixture including and excluding interfaces. The interfaces properties were obtained through pull-off tests. Then, the digital models were applied to conduct virtual tests in order to investigate the internal mechanical response with and without interfaces.

\section{Materials and Methods}

2.1. Materials. The raw asphalt with a penetration grade of 60-80 $(0.1 \mathrm{~mm})$ provided by Shell Road Solutions Xinyue (Foshan) Co., Ltd. was selected as the asphalt binder in this study. Tests of the engineering properties for asphalt binder were conducted according to the Chinese specifications (JTG E20-2011) and detailed properties are provided in Table 1. Crushed diabase stones were used as coarse and fine aggregates and the mineral filler was limestone powder. Tests of the engineering properties were conducted according to the Chinese specifications (JTG E42-2005). The detailed properties of aggregate and mineral filler are provided in Table 2.

The reclaimed asphalt pavement (RAP) materials provided by Guangzhou Municipal Engineering Maintenance Office Co., Ltd. were tested according to the Chinese specifications (JTG F41-2008) in order to obtain the RAP aggregate properties and retained asphalt content. The RAP materials, which are composed of coarse aggregates, fine aggregates, and asphalt binder, were dried and sieved before testing. In this study, the RAP materials with diameter less than $4.75 \mathrm{~mm}$ were removed as shown in Figure 1. The asphalt binder in RAP was extracted by centrifugal separation method and then recovered using Abson method according to the Chinese specifications (JTG F41-2008). The detailed properties of aggregate and retained asphalt binder can be seen in Table 3 .

The dry powder mortar provided by Guangdong Longhu Technology Co., Ltd. was chosen in this study, which is made of cement, sand, and other additives. The gradation of cement mortar is shown in Table 4.

2.2. Sample Preparation. In this study, the standard Marshall method was employed to prepare the test specimens. The procedures for preparing test specimen are provided as follows:

(1) $450 \mathrm{~mm} \times 150 \mathrm{~mm} \times 185 \mathrm{~mm}$ matrix asphalt mixture slab with target air void of $25 \%$ was prepared using standard Marshall method. The specimen was demolded after curing at room temperature for $24 \mathrm{~h}$.

(2) Cement mortar with water-cement ratio of 0.22 and sand content of $30.25 \%$ was prepared according to the gradation of dry powder mortar shown in Table 4 . Before the filling procedure, bottom and edges of the specimen were enclosed with transparent films to prevent cement mortar from flowing out.

(3) The specimen was placed on the vibration table and filled with the prepared cement mortar until there was no bubble appearing on the surface. Then, scrape off the excess cement mortar on the surface of the specimen with a scraper. 
Table 1: Properties of asphalt binder.

\begin{tabular}{lccc}
\hline Properties & Unit & Test results & Test method \\
\hline Penetration at $25^{\circ} \mathrm{C}$ & $0.1 \mathrm{~mm}$ & 71.8 & $\mathrm{~T} 0604$ \\
R\&B softening point & ${ }^{\circ} \mathrm{C}$ & 50 & $\mathrm{~T} 0606$ \\
Ductility at $10^{\circ} \mathrm{C}$ & $\mathrm{cm}$ & 49.4 & $\mathrm{~T} 0605$ \\
Solubility & $\%$ & 99.7 & $\mathrm{~T} 0607$ \\
Flash point & ${ }^{\circ} \mathrm{C}$ & 328 & $\mathrm{~T} 0611$ \\
Density at $15^{\circ} \mathrm{C}$ & $\mathrm{g} / \mathrm{cm}^{3}$ & 1.040 & $\mathrm{~T} 0603$ \\
\hline
\end{tabular}

(4) The transparent films shall be removed when the specimen filled with cement mortar was placed for 24 hours, and then the specimen was placed in a curing box with a temperature of $20^{\circ} \mathrm{C} \pm 3^{\circ} \mathrm{C}$ and a humidity of more than $80 \%$ for curing.

(5) Beam-shape specimens with dimensions of $380 \mathrm{~mm} \times 50 \mathrm{~mm} \times 63 \mathrm{~mm}$ were extracted from the compacted slab.

Brief experimental process is presented in Figure 2. As can be seen from Figure 2(c)), the connectivity voids formed by the aggregates are fully filled by cement mortar, and the materials are in a tight packing state, which shows that the prepared cement mortar has good fluidity, and the design of the matrix asphalt mixture meets the filling requirements.

2.3. Finite Element Modeling. Before reconstructing the finite element model of asphalt mixture based on Figure 2(c), different compositions of the image should be divided first based on segmented method [24]. Basically, the OTSU method was usually utilized for segmentation of the asphalt mixture cross-sectional image. Since warm-mixed reclaimed semiflexible pavement material consists of complex compositions, among which cement mortar and new aggregates are similar in grayscale intensity, it is very difficult to segment the compositions of mixture specimen image by the grayscale-based segmented method. Therefore, the manual method was utilized for segmentation in this study. Segmentation of the cross-sectional image is shown in Figure 3 (new aggregates in red, RAP aggregates in blue, asphalt mastic in yellow, and cement mortar in purple).

In order to obtain the interface zones between different compositions of semiflexible pavement material, the following methods are adopted in this paper: Firstly, individual particles of the same composition were identified and marked, and the binary images of each particle was corroded by the circular shaped structure element of radius 1. Every new binary images of each particle were marked separately. Then, subtraction operations were applied between the new markers and the original markers of the binary images of each particle. The new aggregate-asphalt mastic interface, the RAP aggregate-asphalt mastic interface, and the cement mortar-asphalt mastic interface were obtained according to the subtraction operations results.

A binary image is represented by an $m \times n$ logical matrix, where pixel values are 1 (true) or 0 (false). In order to input the element and node information into the finite element software such as ABAQUS, the node and element numbering rules for generating the pixel-based numerical model are defined as follows: the node and element numbering sequences start from the lower left corner of the matrix and then go to the right side of each line; the last number of each line is followed by the next line. The node and element numbering diagram of the image pixel matrix are shown in Figure 4 . The element and node information are generated with the MATLAB programming and written into an input file of ABAQUS for numerical simulations. The 4-node bilinear reduced integration with hourglass control elements (CPS4R) with a unit length was used in constructing the mesh. The finite element model contained a total of 974,298 elements and 976,642 nodes. Consolidation constraint boundary conditions were applied to the bottom of the digital sample, and the load of $0.7 \mathrm{MPa}$ was imposed to the top of the digital specimen. Figure 5 presents the pixel-based numerical model of asphalt mixture.

\section{Model Parameters Acquisition}

The new aggregates, RAP aggregates, asphalt mastic, and cement mortar used in this study were assumed to be elasticity. The parameters of each composition are shown in Table 5.

In order to analyze the influence of interface weakening on the mechanical properties of the mixed material, the elastic parameters of different interfaces should be obtained. In this paper, the interface parameters of semiflexible materials were obtained by pull-off tests. Details of the pull-off test are as follows: (1) the aggregates were processed into cylindrical specimens with a diameter of $25 \mathrm{~mm}$ and a height of $8 \mathrm{~mm}$, and the cylindrical specimens were put into an oven at $120^{\circ} \mathrm{C}$ and heated for $2 \mathrm{~h}$. (2) The surfaces of different cylindrical specimens were coated with foamed asphalt binder, reclaimed asphalt binder, and foamed asphalt binder + cement mortar, respectively. (3) Two specimens coated with the same binder were installed and the asphalt film thickness was controlled within $15 \mu \mathrm{m}$. Excess asphalt or cement mortar on the side wall of the specimen was scraped off. The prepared specimens coated with cement mortar were placed into a curing box with humidity greater than $80 \%$ and cured for 28 days. (4) Tensile failure tests were carried out at a tensile velocity of $10 \mathrm{~mm} / \mathrm{min}$ and the forcedisplacement curves' results were recorded. Three replicate tests were performed. The interface parameters of the semiflexible material with different boundary were extracted from the force-displacement curves. The flow chart of pulloff test is shown in Figure 6 and the interfacial modulus of warm-mixed reclaimed semiflexible materials is presented in Table 6. 
TABLE 2: Properties of aggregate and mineral filler.

\begin{tabular}{|c|c|c|c|c|}
\hline Materials & Physical properties & Unit & Test results & Test method \\
\hline \multirow{5}{*}{ Coarse aggregate } & Relative apparent density & - & 2.69 & T 0304 \\
\hline & Water absorption & $\%$ & 0.20 & T 0307 \\
\hline & Aggregate crushed value & $\%$ & 20.0 & Т 0316 \\
\hline & Abrasion value & $\%$ & 26 & T 0317 \\
\hline & Flat and elongated pieces & $\%$ & 13 & Т 0312 \\
\hline \multirow{3}{*}{ Fine aggregate } & Relative apparent density & - & 2.68 & T 0328 \\
\hline & Clay content & $\%$ & 2.3 & Т 0333 \\
\hline & Sand equivalent & $\%$ & 72.8 & Т 0334 \\
\hline \multirow{2}{*}{ Mineral filler } & Relative apparent density & - & 2.81 & T 0352 \\
\hline & Moisture content & $\%$ & 0.08 & T 0332 \\
\hline
\end{tabular}

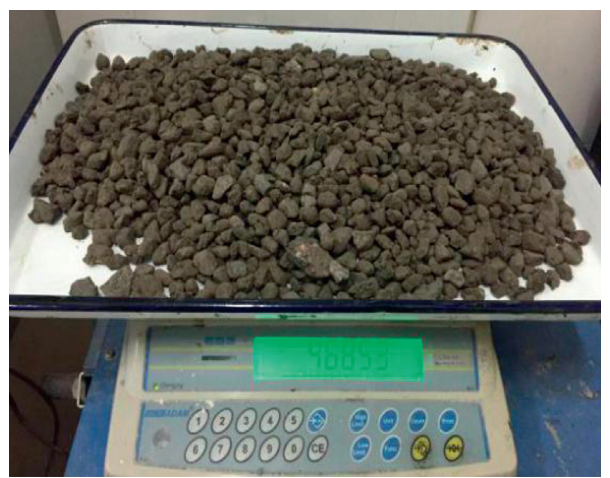

Figure 1: RAP material after drying and sieving.

TABLE 3: Test results of RAP material.

\begin{tabular}{|c|c|c|c|c|}
\hline Materials & Physical properties & Unit & Test results & Test method \\
\hline \multirow{5}{*}{ Asphalt binder in RAP } & Penetration at $25^{\circ} \mathrm{C}$ & $0.1 \mathrm{~mm}$ & 15.1 & T 0604 \\
\hline & Ductility at $15^{\circ} \mathrm{C}$ & $\mathrm{cm}$ & 57 & Т 0605 \\
\hline & Ductility at $25^{\circ} \mathrm{C}$ & $\mathrm{cm}$ & 106 & Т 0605 \\
\hline & R\&B softening point & ${ }^{\circ} \mathrm{C}$ & 71.9 & T 0606 \\
\hline & Dosage & $\%$ & 4.4 & - \\
\hline \multirow{2}{*}{ Coarse aggregate in RAP } & Flat and elongated pieces & $\%$ & 3.4 & T 0312 \\
\hline & Aggregate crushed value & $\%$ & 11.57 & Т 0316 \\
\hline Fine aggregate in RAP & Angularity & $\%$ & 21.14 & Т 0344 \\
\hline
\end{tabular}

\section{Results and Discussion}

In this study, two kinds of two-dimensional microstructural numerical models with and without interfaces were established, and a uniform load was applied to the top of the specimen to investigate the distribution of stress and strain in the material.

4.1. Stress Distribution Analysis. The stress nephograms of the two models are shown in Figure 7. As can be seen from the figures, the red to orange colors in the stress nephogram represent tensile stresses, and the yellow to purple colors in the stress nephogram represent compressive stress. According to the stress distribution nephograms of the two models, it was found that the new and RAP aggregates and cement mortar mostly located in the green area (shown in Figures $7(\mathrm{a})-7(\mathrm{~d}))$, while the asphalt mastic basically located in the yellow area (shown in Figures 7(e) and 7(f)), which indicates that the new and RAP aggregates and cement mortar were subjected to most of the compressive stress, while the asphalt mortar was subjected to most of the tensile stress. In practice, the strength of the warm-mixed reclaimed semiflexible materials is mainly provided by aggregate and cement mortar. So, the stress distributions in the nephograms are consistent with the actual loading distribution in the material.

According to the stress distribution nephogram of the two models, the maximum compressive stress of the new and RAP aggregates and cement mortar with interface is greater than that without interface. As can be seen from the stress nephogram, the areas of new and RAP aggregates, cement mortar, and asphalt mastic in green are larger than those without interface, which indicates that the compressive stress of the material increases when considering the interface. 
TABLE 4: Gradation of dry powder mortar.

\begin{tabular}{lccccc}
\hline Components & Cement & Sand & Fly ash & Heavy calcium & Additive \\
\hline Dosage $(\%)$ & 35 & 30.25 & 10 & 15 & 9.75 \\
\hline
\end{tabular}

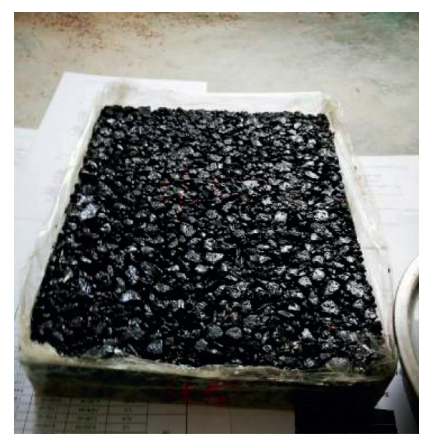

(a)

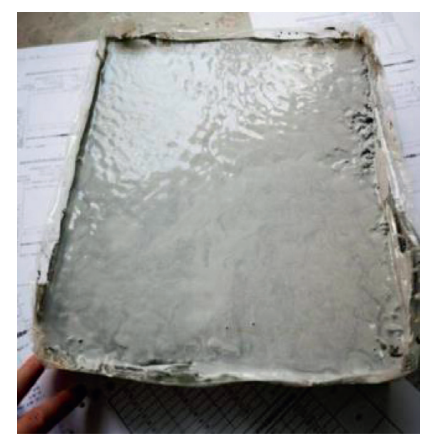

(b)

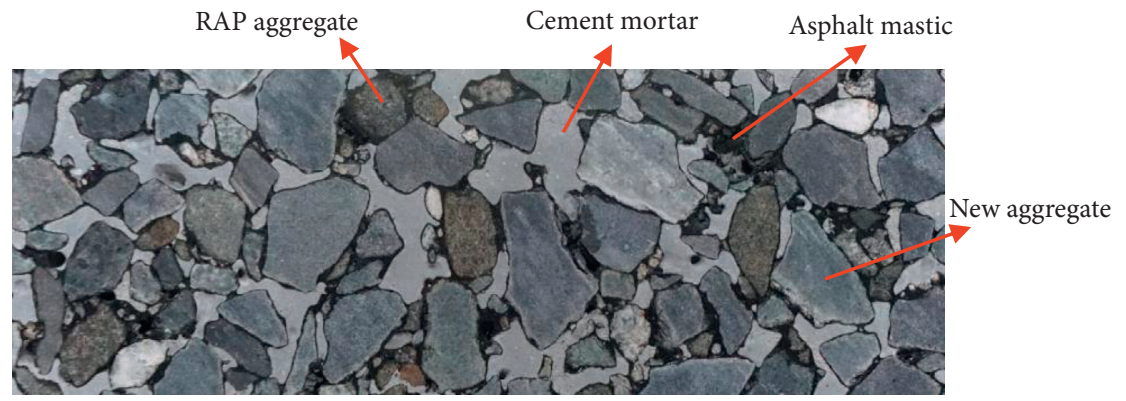

(c)

Figure 2: Brief experimental process of the semiflexible pavement materials: (a) matrix asphalt mixture slabs; (b) slab sample filled with cement mortar; (c) cross section of the semiflexible material.

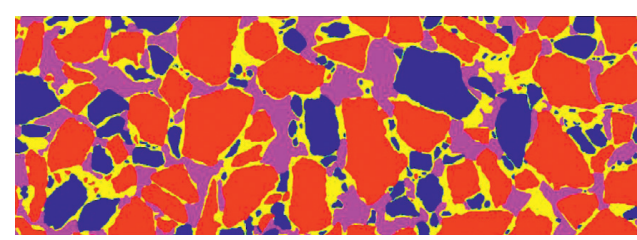

Figure 3: Segmentation of the cross-sectional image.

Three positions shown in Figures 7(a) and 7(b) were selected to investigate the differences of stress in detail. The stresses at three key positions for the two models are presented in Figure 8. As can be seen from Figure 8, the stress values of the microstructural model with interface at positions 1 and 2 are both smaller than those without interface, but the stress values at position 3 are larger than those without interface. The main reason is that the interface area of the warm-mixed reclaimed semiflexible material can absorb part of the stress, which reduces the stress around the interface.

4.2. Strain Distribution Analysis. The strain nephograms of the two models are shown in Figure 9. As can be seen from the figures, the dark red to orange colors in the strain nephogram represent tensile strain, and the orange to purple colors in the strain nephogram represent compressive strain. According to the strain distribution nephogram of the two cases, it is found that the strain is mainly distributed in the cement mortar and asphalt mastic, while small strain occurs only in the local part of aggregate. This is because the aggregates have higher elastic modulus and are much larger than other materials. So the strain on aggregates is minimal, while the strain of materials with low modulus will be slightly larger. In practice, aggregates in the warm-mixed reclaimed semiflexible materials have a large degree of impingement and form a tight skeleton. In addition, the grouting material fills most of the voids, and the cement mortar provides part of the strength after curing. So, the semiflexible material has a strong antideformation ability, and the overall strain distribution is in line with the actual situation. 


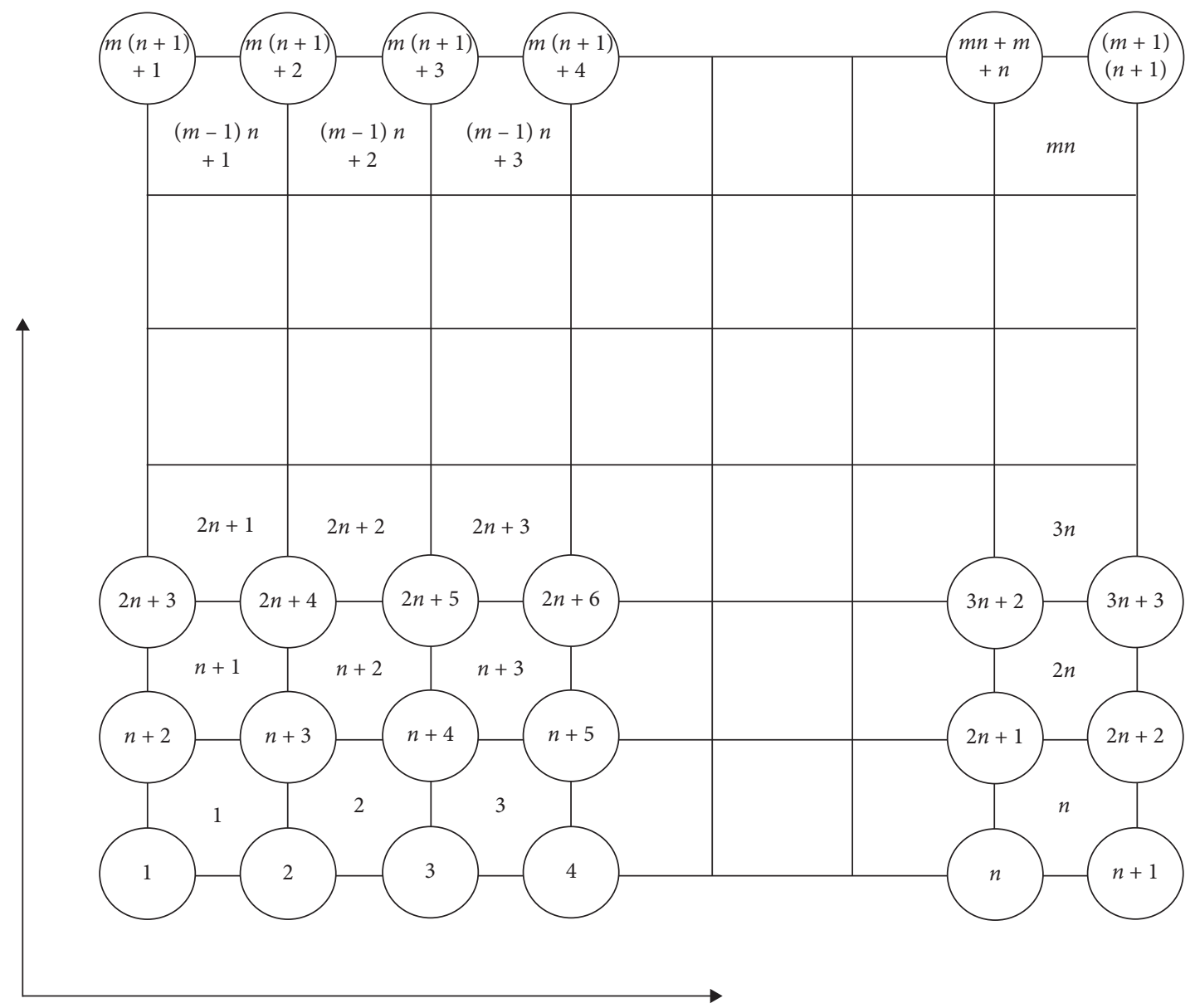

FIGURE 4: Sketch map of elements and nodes label for the image pixel matrix.

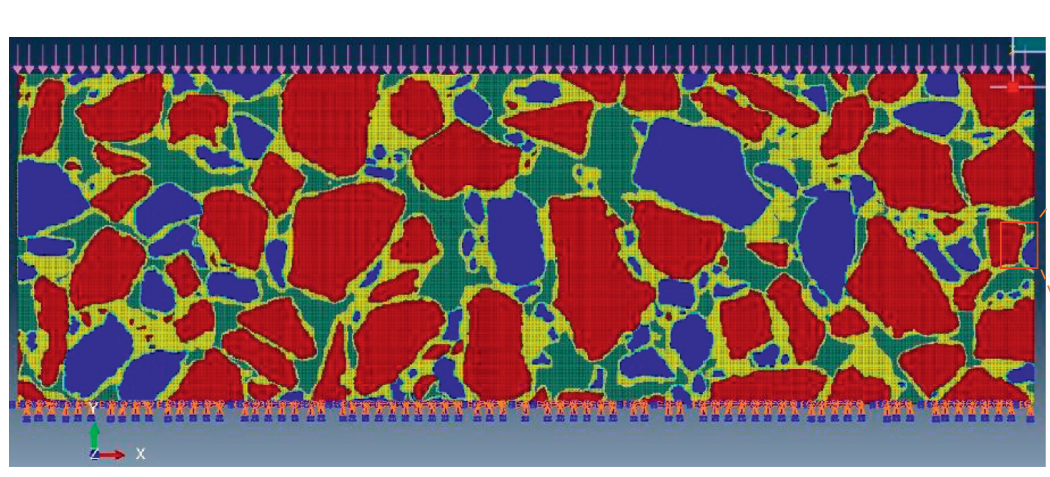

(a)

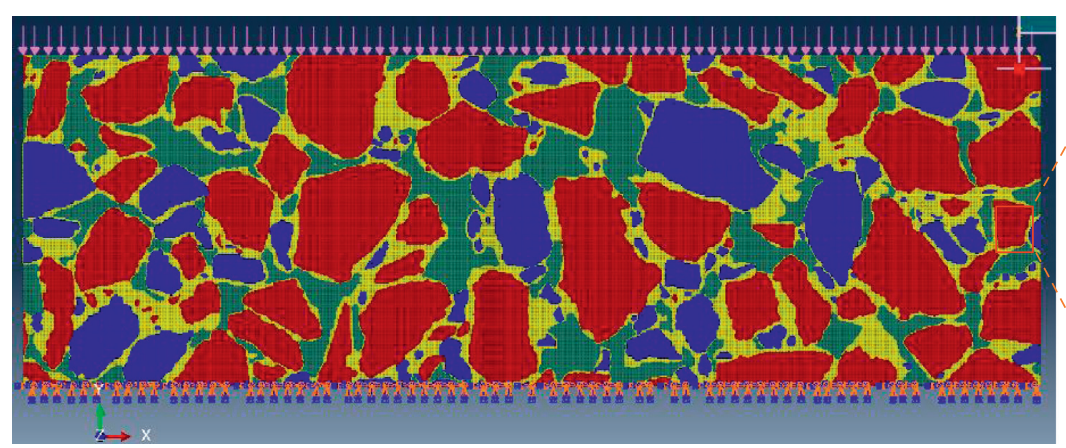

(b)
New aggregate: asphalt

mastic interface Cement mortar: asphalt

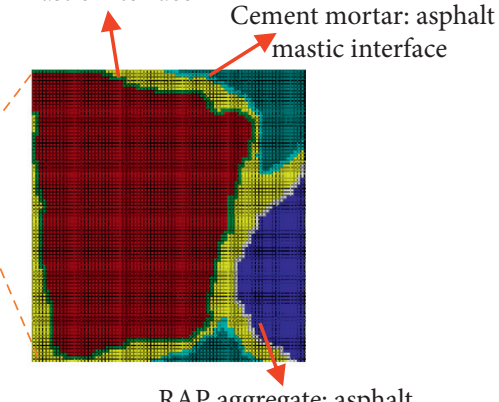

RAP aggregate: asphalt mastic interface

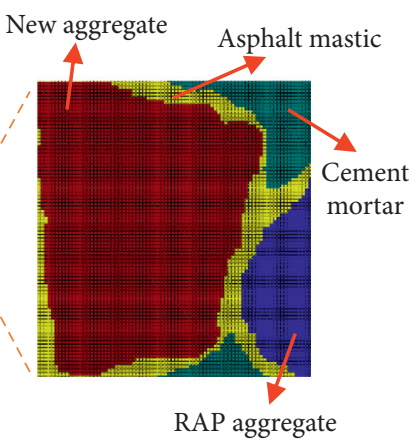

FIGURE 5: Reconstruction of semiflexible pavement material using the finite element method: (a) model with interface; (b) model without interface. 
TABle 5: Parameters of warm-mixed reclaimed semiflexible pavement.

\begin{tabular}{lccc}
\hline Materials & Temperature $\left({ }^{\circ} \mathrm{C}\right)$ & Modulus $(\mathrm{MPa})$ & Poisson's ratio \\
\hline New aggregate (diabase) & - & 70000 & 0.25 \\
RAP (granite) & - & 50000 & 0.28 \\
Asphalt mastic & 25 & 1250 & 0.35 \\
Cement mortar & - & 15000 & 0.30 \\
\hline
\end{tabular}

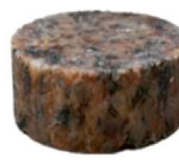

Aggregate cylinder specimen

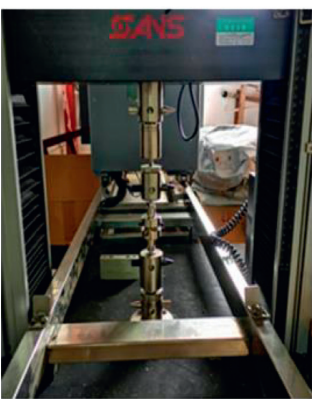

Testing setup

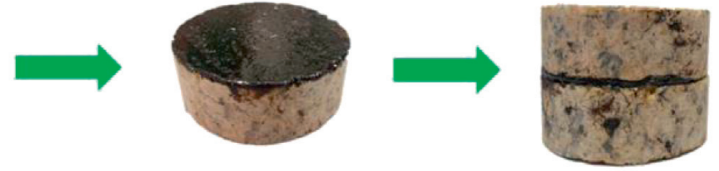

Coated with asphalt film

Specimen installation

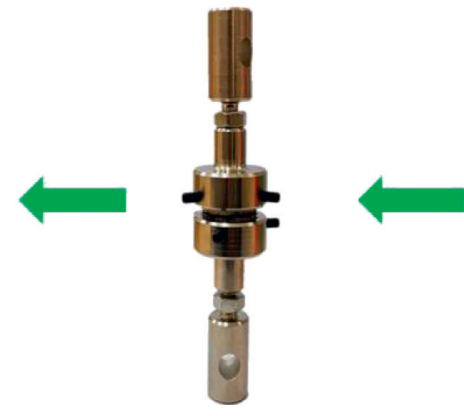

Assembled specimen

Figure 6: Flow chart of pull-off test.
Installed in the clamp

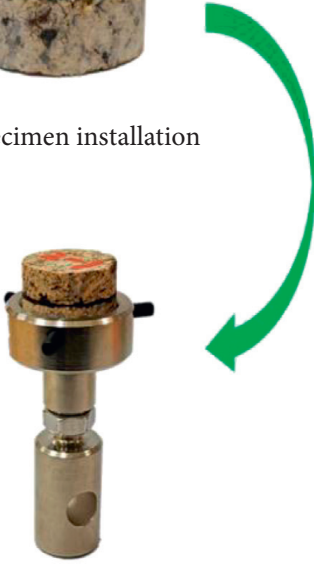

$$
\mathrm{mp}
$$

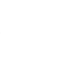




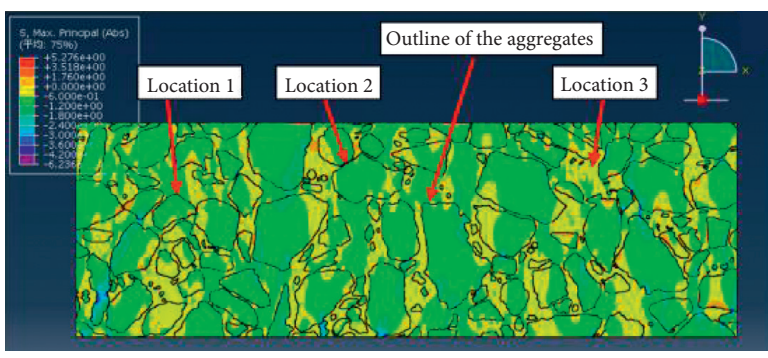

(a)

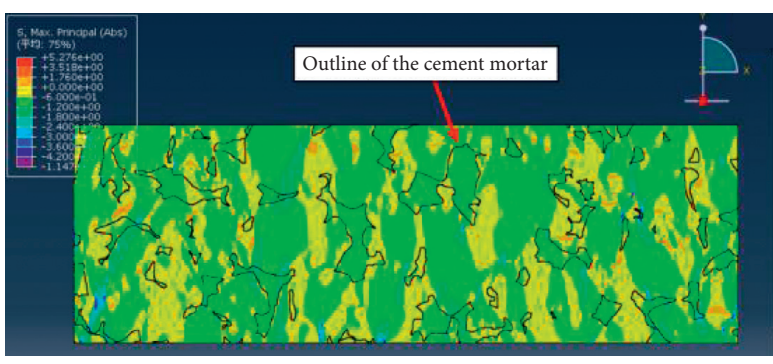

(c)

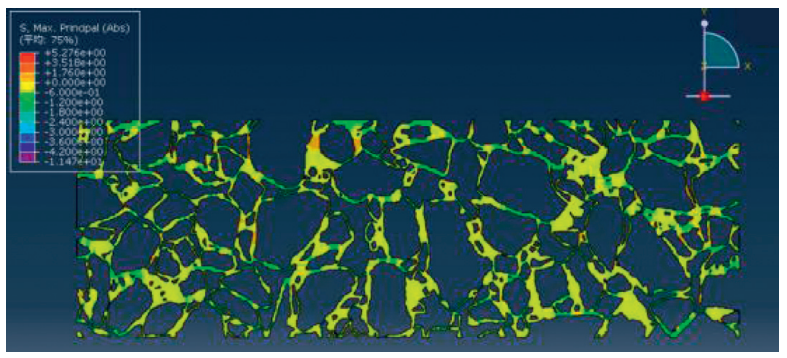

(e)

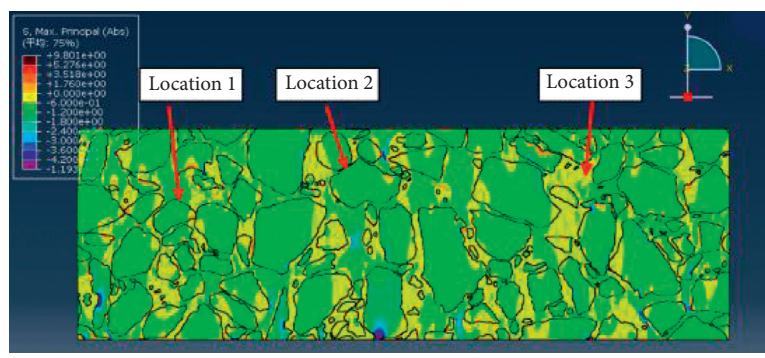

(b)

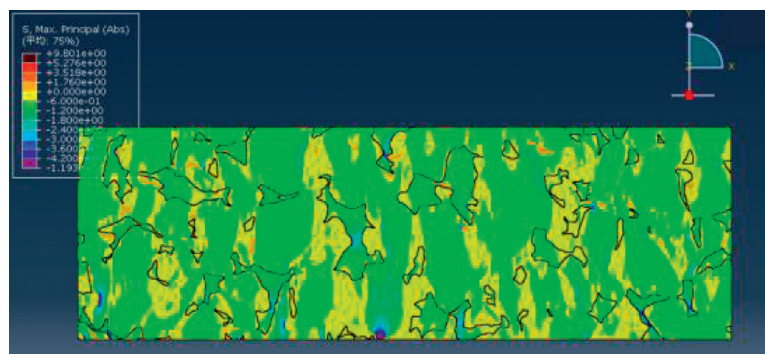

(d)

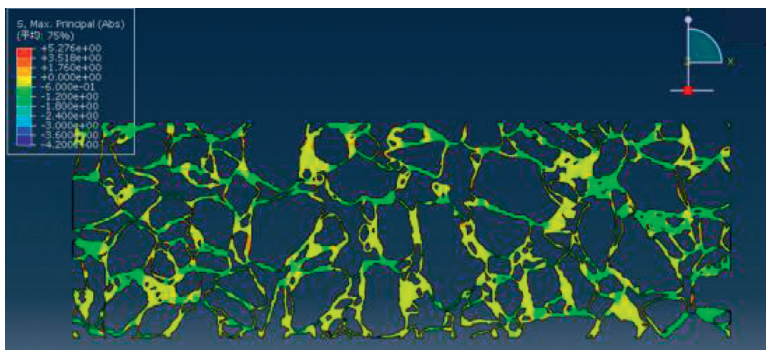

(f)

FIGURE 7: Stress nephogram: (a) aggregates outline with interface; (b) aggregates outline without interface; (c) cement mortar outline with interface; (d) cement mortar outline without interface; (e) asphalt mastic with interface; (f) asphalt mastic without interface.

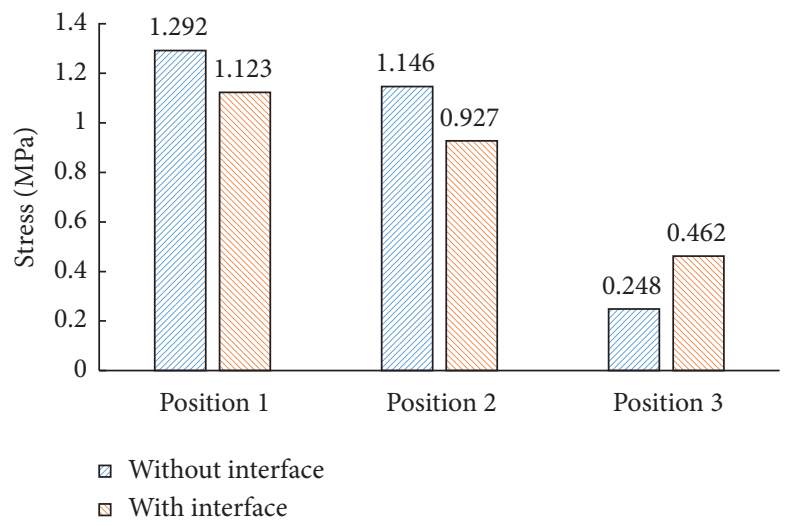

FIGURE 8: Histogram of stress at three key positions. 

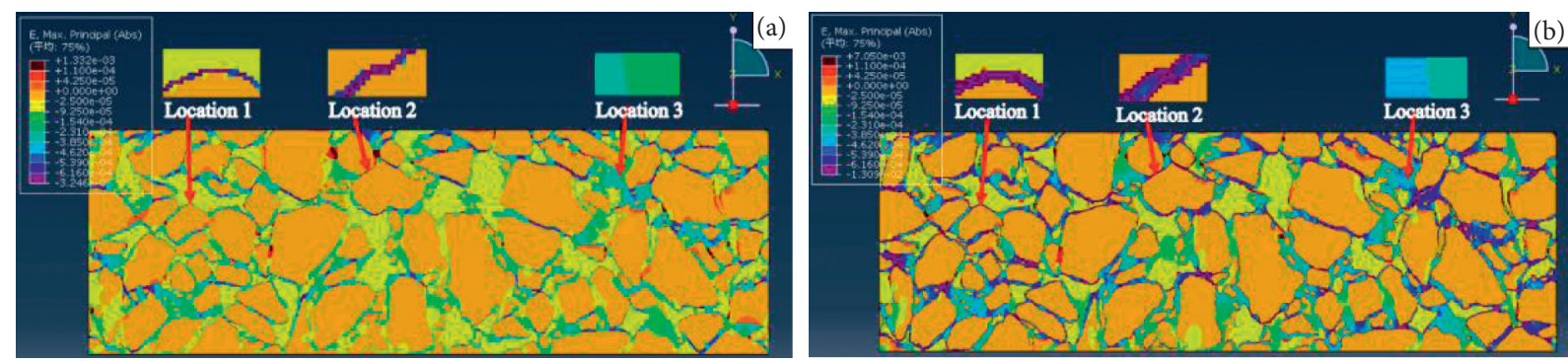

FIGURE 9: Strain distribution diagram of internal structure: (a) with interface; (b) without interface.

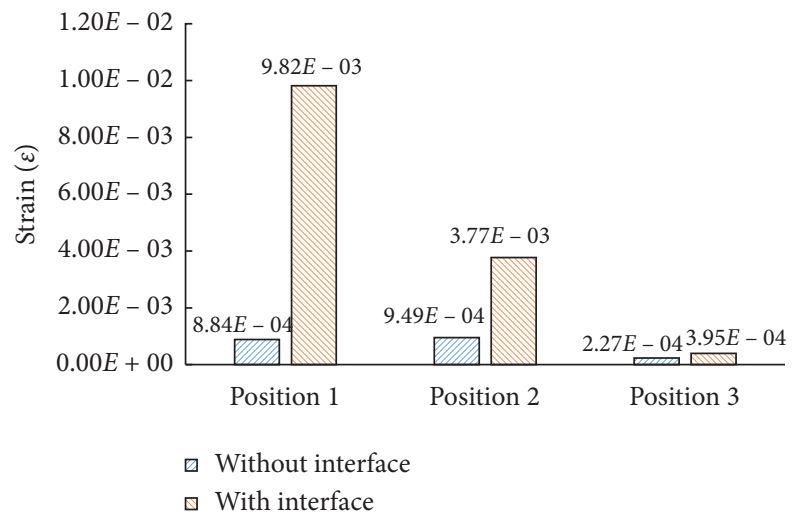

Figure 10: Histogram of strain at three key positions.

\section{Conclusions}

In this paper, the influence of interface weakening of warmmixed reclaimed semiflexible materials on the internal force distribution was investigated through two-dimensional microstructural finite element modeling. Two kinds of twodimensional microstructural numerical models with and without interfaces were reconstructed from digital image slice, and a uniform load was applied to the top of the models to investigate the distribution of stress and strain in the material. The following conclusions were drawn:

(1) The manual method was utilized to separate the different compositions of the asphalt mixture in the image, and pixel-based finite element method was proposed to reconstruct the digital samples. Microstructural finite element models including and excluding interfaces were successfully established.

(2) The maximum compressive stress of the new and RAP aggregates and cement mortar with interface is greater than that without interface, and the compressive stress of the material increases when considering the interface.

(3) Stress values of the microstructural model with interface at positions 1 and 2 are both smaller than those without interface, but the stress values at positions 3 are larger than those without interface. The main reason is that the interface area of the warm-mixed reclaimed semiflexible material can absorb part of the stress, which reduces the stress around the interface.
(4) The maximum compressive strain of the material with interface is greater than that without interface and the strain values in the models with interface at all three positions are greater than those without interface.

(5) Strain values in the models with interface at all three positions are greater than those without interface. The main reason is that the aggregates and the asphalt mastic coated with cement mortar form a network structure, and the load needs to destroy the interface structure before it can be further transferred.

\section{Data Availability}

The data used to support the findings of this study are included within the article.

\section{Conflicts of Interest}

The authors declare that there are no conflicts of interest regarding the publication of this paper.

\section{Acknowledgments}

This work was supported by the Science and Technology Program of Nanning (no. 20193129), Key Research and Development Plan of Guangxi (no. AB19245019), and Open Project of Guangxi Key Lab of Road Structure and Materials (no. 2018gxgclkf003). The authors thank all those who contributed to the image technique and the experimental 
part of this study. In addition, the authors acknowledge the National Supercomputer Center (NSCC) in Guangzhou for providing computing resources useful in conducting the research reported in this paper.

\section{References}

[1] J.-F. Su, E. Schlangen, and J. Qiu, "Design and construction of microcapsules containing rejuvenator for asphalt," Powder Technology, vol. 235, pp. 563-571, 2013.

[2] A. M. Tahir, K. Khailesh, R. Vishnu, and C. Venkaiah, "Performance evaluation of rejuvenated recycled asphalt blends at high and intermediate pavement temperatures," International Journal of Pavement Engineering, pp. 1-13, 2021.

[3] D. Li, L. Zhen, F. Zou, and H. Yu, "Effects of rubber absorption on the aging resistance of hot and warm asphalt rubber binders prepared with waste tire rubber," Journal of Cleaner Production, vol. 303, Article ID 127082, 2021.

[4] P. Guo, S. Chen, F. Xie et al., "Influence of coarse aggregate morphological properties on the performances of warm-mix asphalt containing recycled asphalt pavement," Journal of Materials in Civil Engineering, vol. 33, no. 5, Article ID 04021081, 2021.

[5] J. Wang, N. Su, F. Xiao, and N. Amirkhanian Serji, "Dynamic modulus characteristics of mixtures containing recycled asphalt pavements, warm mix additives, and antistrip agents," Journal of Testing and Evaluation, vol. 49, no. 3, Article ID 20200006, 2021.

[6] M. Guo, M. Liang, S. Anand, B. Amit, and D. Luo, "Characterization of rejuvenation of various modified asphalt binders based on simplified chromatographic techniques," International Journal of Pavement Engineering, pp. 1-11, 2021.

[7] M. Guo, X. Liu, Y. Jiao, Y. Tan, and D. Luo, "Rheological characterization of reversibility between aging and rejuvenation of common modified asphalt binders," Construction and Building Materials, vol. 301, Article ID 124077, 2021.

[8] M. Guo, M. Liang, Y. Fu, S. Anand, and B. Amit, Average Molecular Structure Models of Unaged Asphalt Binder Fractions, Materials and Structures, Springer Nature, Basingstoke, UK, 2021.

[9] S. Mo, Y. Wang, F. Xiong, C. Ai, D. Wang, and T. G. Y. Amy, "Changes of asphalt fumes in hot-mix asphalt pavement recycling," Journal of Cleaner Production, vol. 258, Article ID 120586, 2020.

[10] H. Chamod, X. Hou, J. Wang, and F. Xiao, “A comprehensive review on the utilization of reclaimed asphalt material with warm mix asphalt technology," Construction and Building Materials, vol. 227, Article ID 117096, 2019.

[11] L. Qiang, G. Sun, Y. Lu, Y. Meng, S. Luo, and L. Gao, "Effects of warm-mix asphalt technologies and modifiers on pavement performance of recycled asphalt binders," Journal of Cleaner Production, vol. 282, Article ID 125435, 2020.

[12] S. Liu, S. Zhou, and A. Peng, "Laboratory evaluation of foamed warm mix binders and mixtures containing reclaimed asphalt pavements," Construction and Building Materials, vol. 258, Article ID 119773, 2020.

[13] K. Amir and M. Seyed Mohsen, "Fracture and mechanical properties of water-based foam warm mix asphalt containing reclaimed asphalt pavement," Construction and Building Materials, vol. 269, Article ID 121332, 2021.

[14] P. F. Abreu Liliana, R. M. Oliveira Joel, M. R. D. Silva Hugo, P. Daniela, and V. Fonseca Paulo, "Suitability of different foamed bitumens for warm mix asphalts with increasing recycling rates," Construction and Building Materials, vol. 142, pp. 342-353, 2017.

[15] J. Pei, J. Cai, D. Zou et al., "Design and performance validation of high-performance cement paste as a grouting material for semi-flexible pavement," Construction and Building Materials, vol. 126, pp. 206-217, 2016.

[16] J. Cai, J. Pei, Q. Luo, J. Zhang, L. Rui, and X. Chen, "Comprehensive service properties evaluation of composite grouting materials with high-performance cement paste for semi-flexible pavement," Construction and Building Materials, vol. 153, pp. 544-556, 2017.

[17] M. Gong, Z. Xiong, H. Chen et al., "Evaluation on the cracking resistance of semi-flexible pavement mixture by laboratory research and field validation," Construction and Building Materials, vol. 207, pp. 387-395, 2019.

[18] Y. Gong, H. Bi, C. Liang, and S. Wang, "Microstructure analysis of modified asphalt mixtures under freeze-thaw cycles based on CT scanning technology," Applied Sciences, vol. 8, no. 11, pp. 1-14, 2018.

[19] W. Huang, X. Cai, L. Xiang, and K. Wu, "Influence of nominal maximum aggregate size and aggregate gradation on pore characteristics of porous asphalt concrete," Materials, vol. 13, p. $1355,2020$.

[20] J. Hu, P. Liu, D. Wang, and M. Oeser, "Influence of aggregates' spatial characteristics on air-voids in asphalt mixture," Road Materials and Pavement Design, vol. 19, no. 4, pp. 837-855, 2017.

[21] T. Schüler, R. Jänicke, and H. Steeb, "Nonlinear modeling and computational homogenization of asphalt concrete on the basis of XRCT scans," Construction and Building Materials, vol. 109, pp. 96-108, 2016.

[22] W. Huang, H. Wang, Y. Yin, X. Zhang, and J. Yuan, "Microstructural modeling of rheological mechanical response for asphalt mixture using an image-based finite element approach," Materials, vol. 12, no. 13, p. 2041, 2019.

[23] W. Huang, Z. Ren, X. Zhang, and J. Yu, "Investigation on microstructural damage properties of asphalt mixture using linear and damage-coupled viscoelastic model," Applied Sciences, vol. 9, no. 2, pp. 1-19, 2019.

[24] W. Huang and X. Zhang, "Segmentation of coarse aggregate adhesion images using morphological multiscale algorithm," Journal of Harbin Institute of Technology, vol. 48, no. 3, pp. 125-130, 2016. 